\title{
Current Wind Tunnel Capability and Planned Improvements at Lewis Research Center
}

\author{
(NASA-TH-87190) CURRENT WIND TUNNEL \\ CAPABILITY AND FLANNED IAPROVEUENTS AT LEAIS \\ RESEARCH CENTER (NASA) 24 P BC AO2/MF AO1 \\ CSCL 14B
}

David N. Bowditch

Lewis Research Center Cleveland, Ohio

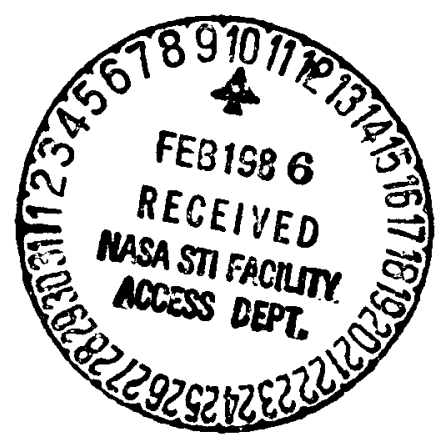

Prepared for the

14th Aerodynamic Testing Conference sponsored by the American Institute of Aeronautics and Astronautics West Palm Beach, Florida, March 5-7, 1986 


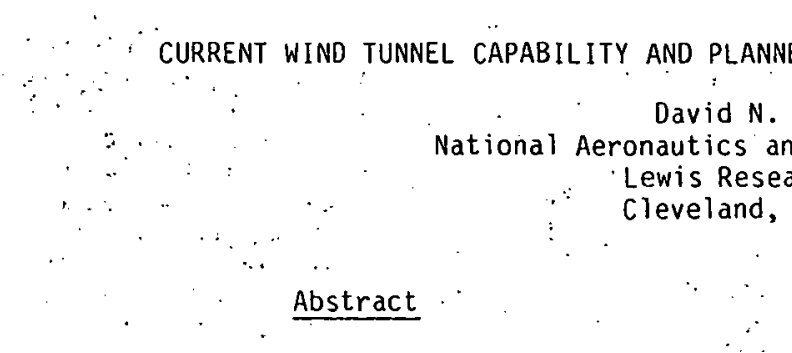

As the propulsion and power generation center of NASA, Lewis has designed its wind tunnels for propulsion research. Therefore, the 8 by 6 foot Supersonic Wind Tunnel and the 10 by 10 Foot Supersonic Wind: Tunnel provide the capability to test operating propulsion systems from Mach 0.4 to 3.5 . The 9 by 15 Foot Wind Tunnel can investigate propulsion installation problems at the lower take-off and landing speeds and provides an excellent anechoic environment to measure propeller and fan noise. The Lewis Central Air System provides steady air supplies to $450 \mathrm{psi}$, and exhaust to $3 \mathrm{in}$. of mercury absolute, which are available to the wind tunnels for simulation of jets and engine induced flows. The Lewis Icing Research Tunnel is the largest in the free world that can produce icing conditions throughout the year. Rehabilitation of the Altitude Wind Tunnel at Lewis would allow testing of propulsion systems in the upper left hand corner which would be a unique capability. Also, in a mothiballed state at Lewis, the Hypersonic Tunnel Facility could provide the best simulation of nonvitiated Mach 5-7 test conditions available. Studies' are currently being 'made of the Lewis facilities to identify enhancements of their research potential for the 1990's and beyond.

$$
\therefore \text {. . Introduction }
$$

The NASA Lewis Research Center was started in the early forties, and its wind.tunnels were built from then until the late $1960^{\prime} s$. As the propulsion center of NACA and NASA, Lewis' tunnels are unique within NASA in that they were designed to investigate propulsion problems. Therefore, the two major wind tunnels can test operating engines over the Mach number $r$ ange from 0.4 to 3.5 .

The major wind tunnels at Lewis and their supporting facilities are listed on the first figure. The 9 by 15 and 8 by 6 Foot Wind Tunnels are in a single circuit, and cover the speed range from take-off and landing through transonic to Mach 2.0. The 10 by 10 Foot Supersonic Wind Tunnel then extends that speed range to Mach 3.5. The Icing Research Tunnel has a 6 by 9 foot cross-section, and is the largest tunnel in the free world able to produce icing conditions throughout the year.. The 1 by 1 Foot Wind Tunnel is driven by Lewis' Central Air. System (CAS) which has the capacities listed on the lower portion of the figure. The compressors and exhausters of the Central Air System are located in the Propulsion System Laboratory Equipment Building in the upper center of the second figure and the Engine Research Building (ERB) in the right center of the figure. As is apparent in this figure, these CAS services are available to the wind tunnels for simulation of propulsive jets, "to drive air turbine propulsion simulators, and to induce propulsion flows into inlets. - These capabilities will. be described in each of the facility descriptions.
The 8 by $6 / 9$ by 15 Foot Wind Tunnels.

The 8 by 6 foot Wind Tunnel, shown in 'Fig. 3 ; was first operated as a supersonic wind tunnel from Mach 1.5 to 2.0 in 1949. The initial tunnel only had the conical diffuser downstream of the test section, and resulting noise problems caused the addition of an acoustically treated structure throughout the first and second turns. To save the dry air needed for supersonic testing, the circuit was completed in 1955, including a cooler to reinove the drive heating. Also, the test section was perforated to a porosity of 6 percent with $60^{\circ}:$ holes to provide continuous test capability from Mach 0.36 to the original design maximum Mach number. of 2.0 . In 1969, to investigate the propulsion problems of STOVL, a 9 by 15 foot test section was completed just downstream of the cooler in the back leg of the circuit.

Due to its unusual location in the wind tunnel circuit, the 9 by 15 Foot Wind Tunnel 1 has unusuily quiet operation. It is separated from the drive compressor by the large air dryer downstream of the test section and by the large acoustic absorption structure in the upstream direction. 'The test section was first lined with acoustically absorbing walls to investigate fan noise with the results shown in $\mathrm{Fig} .4 .^{2}$ Since frequencies above $1000 \mathrm{~Hz}$ fell off at $20 \mathrm{db}$ per decade, the test section provided the ability to measure free field noise with forward velocities equal to take-off and landing aircraft. This allowed the firs'temonstration in a ground facility of the forward velocity effect on fan noise shown in Fig. 5. Here the increased fan noise, due to its interaction with the stretched vortices inherent in static operation, disappears as forward velocity increases. "This acoustic capability has been further increased with the addition of new wall treatment $1 \mathrm{ft}$ thick, (shown in Fig. 6) which will decrease the frequency for free field simulation to $250 \mathrm{~Hz}$. Also shown in the figure is the $1000 \mathrm{hp}$ propeller drive which is driven by the CAS, 450 psi air system. This new capability will provide propeller noise data throughout the take-off and landing regime for development of new advanced turboprop aircraft. The CAS air systems also provide the air to drive ejectors for STOVL concepts such as the ejectior-inwing model shown in Fig. 7. This model test successfully demonstrated that the ejector operation could be started in forward flight which corresponds to conversion from wing supported flight to propuision support. Using the CAS 450 psi system to simulate a reversed jet, and the CAS exhaust system to induce the appropriate inlet flow, allows hot gas reingestion to be studied, as shown in fig. 8. With the current concern about runway damage during wartime, the use of thrust reversal on future fighter aircraft is highly probable, and the 9 by 15 Wind Tunnel capability provides an excellent resource to develop successful thrust reversal systems. This testing will be further enhanced by the addition of a $1000^{\circ} \mathrm{F}$ heater to the CAS 450 ps $i$ 
air system to better simulate the density difference between the exhaust gas and the free stream air.

The 8 by 6 Foot Wind Tunnel test section characteristics are shown on Fig. 9. ${ }^{3}$ The variation of altitude and total temperature are shown as a function of test section Mach number. Since the drive compressor always has an atmospheric inlet, essentially a single altitude is provided at each Mach number. The compressor location upstream of the test section provides a relatively. low altitude (nigh Reynolds number) and also makes the drive invulnerable to model structural failure. In fact, simulated munitions have been purposely dropped from models to investigate separation characteristics.

With the 8 by 6 Foot Wind Tunnel initiating operation in 1949 , most of the early supersonic fighter inlets were developed in its test section. Its cros's section allows relatively high angles of attack and yaw to be investigated throughout the Mach number range of most interest for fighter aircraft. A typical installation shown in Fig. 10 for the HIMAT remotely piloted vehicle investigated the inlet performance, and both instantaneous and time averaged distortion. The wind tunnel data systems have the ability to quickly record both the large number of dynamic and steady state data channels characteristic of this type of testing.

Recently, testing in support of the Advanced Turboprop Program has occupied the schedule of the 8 by 6 foot Wind Tunnel. A recent model of a counter rotation propeller is shown in Fig. 11 . Counter rotating turbines driven by the CAS 450 psi air system are used to power the propellers, and telemetering is used to acquire the stress, pressure, and temperature data from the rotating shafts. Models such as this are used to obtain aerodynamic and aeroelastic performance and acoustics on both single and counter rotation propeller models. Probing of the flow field of the rotating propeller has been obtained with the laser doppler velocimeter equipment shown in Fig. 12. To obtain laser data in the hostile environment of the transonic wind tunnel, it was necessary to separately mount the laser and its optics on its own foundation and contain it in an acoustically treated box. Lasers nave also been used to obtain the aeroelastic characteristics of model propellers as shown in Fig. 13. Here, the interruption of accurately placed laser beams is carefully compared to a once-per-revolution signal to determine the steady and dynamic operating shape of the propelier blades. Acoustic data has also been measured in the 8 by 6 Foot Wind Tunnel by flush, wall-mounted transducers, both at the tunnel wall and on plates aligned with the flow near the propeller. A comparison of such measurements with flight data and data from anechoic wind tunnels is presented in Fig. 14.4 Excellent agreement is evident, which is not completely understood at this time, due. to the apparently poor acoustic environment. However, the very directive nature of the propeller sound field, and the sweeping of the sound field downstream by the transonic forward speed, makes the waves reflected from the walls travel much longer paths than the direct waves to the flush microphones. Therefore, the direct sound is much stronger than the reflections which appears to make an accurate measurement possible.
Rehabilitation of the 8 by. 6 Foot Supersonic Wind Tunnel was initiated recently with the rewind of the drive motors and the addition of new motor controls. Expansion of the control room and upgrade of the air dryer are currently planned. other improvements being considered include (1) improvement of test section flow quality through better control of the flow in the return circuit, (2) productivity enhancements to improve model handling and mounting, and (3) a modern test section.

\section{0 by 10 Foot Supersonic Wind Tunnel}

The Lewis 10 by 10 Foot Supersonic Wind Tunne ${ }^{5}$ was built under the Unitary Wind Tunnel Act, and started operation in 1956. Its circuit is depicted in Fig. 15. Its primary drive compressor at the upper left has 150000 horsepower and will. operate the wind tunnel from Mach 2.0 to 2.8. During this operation, the flow goes around the secondary compressor through the outer leg at the right of the figure. From Mach 2.8 to 3.5 , the valve in the outer leg is closed; and the secondary compressor (100 000 horsepower) provides the addi-. tional pressure ratio necessary to operate at the higner Mach numbers. To operate on the propulsion cycle, the pressure in the back leg of the tunnel is brought to atmospheric, and a 24 foot diameter valve is swung across the circuit to open the entrance to an acoustic muffler through which all the tunnel flow exhausts. All the flow then enters the tunnel through the air dryer at the top of the figure which contains 1800 tons of activated alimina which drys the air to a dew point of $-20^{\circ} \mathrm{F}$. A two dimensional flexible nozzle upstream of the test section is accurately positioned at each tenth of a Mach number. Local, exhausters allow the altitude to be varied on the aerodynamic cycle. The CAS high pressure air and exhaust are available for propulsion simulation. The altitude variation with Mach number is shown in Fig. 16. While a wide range of altitudes are available on the aerodynamic cycle, only a single altitude is possible at each Mach number on the propulsion cycle, due to exhausting the entire tunnel flow to atmosphere. Temperature simulation in the wind tunnel is shown on the right of Fig. 16. The minimum temperature corresponds to the cooling available from the two water coolers in the circuit. A combustion heater in the bellmouth of the tunnel provides the ability. to heat the air to $630^{\circ} \mathrm{F}$ with moderate vitiation. This allows simulation of actual air temperatures up to Mach 3.0.

A typical propulsion integration model is shown in Fig. 17 mounted in the 10 by 10 Foot Supersonic Wind Tunnel. To determine the installed performance of the nozzles, the CAS 450 psi air is used to simulate the propulsive jet. The Lewis tunnels have supported launch vehicle development, and typical Space Shuttle testing in. the 10 by 10 Foot Supersonic Wind Tunnel is shown in Fig. 18. Aerodynamic data was obtained to investigate pressure loads, control signals on the shuttle nose, and booster stability during re-entry and recovery. Also, base heating was investigated in the 10 by 10 Foot Supersonic Wind Tunnel by measuring heating rates over the model base during firing of actual solid propellants in the boosters and hydrogen and oxygen in the main engines. Results of such tests were used to determine the necessary insulation to protect the shuttle from hot gas recirculation. A typical airbreathing propulsion installation is 
shown in Fig. 19. In this test, a TF 30 afterburning turbofan engine was investigated with a supersonic inlet containing supersonic internal compression. Propulsion system dynamics-andcontrol were investigated and successful operation of the propulsion system throughout the Mach number range was demonstrated. Operation through an unstart and restart cycle, which is characteristic of these highly efficient inlets, was also demonstrated.

Rehabilitation of the 10 by 10 Foot Supersonic Wind Tunnel is currently being considered for 1989. This would include rewind of the drive motors, and improved model handling. Extending the speed range of the tunnel to Mach 4.0 is also being considered. By reducing losses in the wind tunnel diffuser througn boundary control, the terminal shock of the tunnel could be kept downstream of the test section with the current drive power. The wind tunnel flexible wall nozzle is capable of providing the higher speed positions, so that only the diffuser modification is necessary to obtain the higher speeds.

\section{Small Wind Tunnels}

The Lewis CAS provides the opportunity to operate several small wind tunnels. A typical example is shown in Fig. 20 which presents the 1 by. 1 Foot Supersonic Wind Tunnel. It can operate at Mach numbers from 1.3 to 4.0 by changing blocks like the one shown in the lower right of the figure. Plans are currently being formulated to extend the,speed to higher Mach numbers either in the 1 by 1 tunnel circuit or another location on the CAS. Another wind tunnel operating on the CAS is the Altitude Wind Tunnel model which is a $2 \mathrm{ft}$ octagonal transonic tunnel. It will be acoustically treated to provide a very quiet environment. This wind tunnel will provide Lewi.s with an excellent research facility after the AWT modeling is completed.

\section{6 by 9 Foot Icing Research Tunnel}

The Icing Research Tunnel (IRT) described in Fig. 21 is the largest. icing wind tunnel in the free world that can generate icing conditions throughout the year. 6 Its 2100 ton refrigeration system was initially built as a part of the old Altitude Wind Tunnel which was one of the original Lewis facilities. It allows total. temperatures of -20 $\mathrm{F}$ to be obtained in the tunnel flow which is combined with the cloud spray system to generate a simulated icing environinent. Mach numbers from 0 to 0.4 can be obtained in its 6 by 9 foot test section. The facility was first operated in 1944 and was very active through the 1950's until the technology for the deicing and anti-icing technologies for commercial transport aircraft was developed. In the 1970's, interest in all-weather operation of helicopters and general aviation aircraft rekindled interest in icing research to generate new deicing techniques that did not need the large amounts of hot air required by the earlier technology. Recently, the IRT has been Lewis' busiest tunnel and operated over $1000 \mathrm{hr}$ during 1985. Typical research accomplished in the IRT is presented in Fig. 22. The icing of wings, helicopter rotors, armament, and inlets, and basic research on ice shapes have recently been studied.
Recently, a major effort has been directed at verifying the ability of. the IRT to simulate the flight icing environment by comparing results with those obtained on a flight program using a Twin Otter aircraft. A large part of this effort is being aimed at expanding the ability to simulate the icing cloud conditions as shown in Fig. 23. The FAA icing cloud conditions are presented by the heavy lined envelopes which were derived. from flight and are plotted in terms of liquid water content and water droplet volume median diameter. The 1979 capability to simulate the FAA FAR 25 conditions is shown on the figure for speeds of 150 to $260 \mathrm{mph}$ and covered only a small-portion of the total icing conditions. Recent work on spray nozzles and nozzle arrays on the tunnel spray bars has predicted the expanded region of icing simulation at 100 to $270 \mathrm{mph}$.planned for. 1986 . The IRT is currentiy being rehabilitated by replacing the drive motor, wind tunnel controls, and spray bar system. A new eight bar spray system utilizing CAS 450 psi air in new spray nozzles is responsible for the new expanded capability. Another improvement being considered is an insert to the test section which could provide speeds to Mach 0.7 when combined with fan modifications to provide the necessary increased pressure ratio.

\section{Altitude Wind Tunnel}

Ever since the Lewis Altitude Wind Tunnel was turned into space tanks in the early 1960's, there has not been a wind tunnel in the United States that was capable of testing a propulsion system at the low temperature and pressure characteristics of the "upper left hand corner." These conditions can only be produced in an altitude engine test facility in the connected pipe mode or with a relatively small free jet. The Lewis effort to. rehabilitate the AWT ${ }^{7}$ would have eninanced the earlier capability which is currently missing in. the United States. Figure 24 presents the ability of current wind tunnels to simulate the actual pressures and temperatures experienced in flight. Most of the tunnels are atmospheric at some point in their circuit during propulsion operation and, therefore, can simulate essentially a single.pressure altitude at each Mach number. Orily the AEDC 165 and $16 T$ wind tunnels have the ability to: operate over a range of pressure altitudes during propulsion operation. This requires a scoop to remove the engine exhaust and pump it back to atmospheric pressure. Only a portion of the AEOC tunnel operating envelope is shown on the figure because that is the only portion of the envelope where both flight pressure and temperature can be simulated. In general, the existing tunnels are limited in temperature simulation by the minimum temperature obtained with water cooling. As can be seen, the AWT would have had the only wind tunnel capability to operate in the "upper left hand corner."

The requirement for operation in the "upper left hand corner" is best illustrated by the example of testing a turboprop, which is presented in Fig. 25. The expected difference between normal flight conditions and those in an unrefrigerated wind tunnel are shown. Aerodynamic similarity requires that $N / \sqrt{T}$ (or tip Mach number) be held constant. This requires that the propeller be oversped by 12 percent in the hot tunnel, which will increase the centrifugal stresses by

25 percent. This causes changes in the blade twist 
and significantly changes the aeroelastic characteristics. The propeller operating speed is mismatched to the engine excitation frequency, and the engine, which is matched for flight conditions, can probably not provide the necessary power in the hot tunne1. Therefore, there is no ground facility currently available to test a turboprop propulsion system (since free jets in an engine test facility: are too small) and no wind tunnel in which a turbine engine can be tested with an inlet under conditions characteristic of the "upper left hand corner."

The planned modifications to the AWT shell are shown in Fig. 26. The heat exchanger is its most unique component, which would be cooled with freon from a 21000 ton refrigeration system. The $20 \mathrm{ft}$ octagonal test section would be bled by a 1 arge plenum evacuation system in order to allow the testing of large blockage models at high subsonic Mach numbers. Increased drive power and a new $f$ an would provide an increase in Mach number from 0.6 to over 0.9. Interchangeable bellmouth hardware would allow the flow conditioners required for low turbulence to be replaced with a water spray system to provide an icing simulation capability. The turning vanes must be steam heated during the icing testing. Also, an exhaust scoop for removing combustion products is necessary to allow engine testing at high altitude. Lewis has currently stopped advocacy of the AWT rehabilita$t$ ion, but that leaves a significant hole in the United States' test capability.

\section{Hypersonic Tunnel Facility.}

The Hypersonic Tunnel Facility (HTF), is a b lowdown enclosed free-jet tunnel designed for propulsion testing with temperature, composition, and altitude simulation over the Mach number range of 5 to 7 . The facility is described in more detail in Ref. 8 and a schematic of the facility is presented in Fig. 27. The facility uses an inductionheated, drilled-core graphite storage heater to heat nitrogen to a nominal temperature of $4500^{\circ}$ Rankine at a maximum design pressure of $1200 \mathrm{psi}$. The nitrogen is mixed with ambient-temperature oxygen to produce synthetic air. Diluent nitrogen is added with the oxygen in the mixer at tunnel operating Mach numbers below 7 to supply the correct weight flow to the 42 in.-exit-diameter freejet nozzles. Altitude simulation is provided by a diffuser and single stage steam ejector. Three interchangeable axisymmetric contoured nozzles provide nominal test Mach numbers of 5,6 , and 7 . Maximum run times are estimated to be 2 to $3 \mathrm{~min}$, depending on Mach number and altitude: A cut-away of the test section is shown in Fig. 28 with a typical ramjet engine installed. The facility is currently mothballed," but could be rehabilitated and operated for a fraction of the cost of the construction of an equivalent new facility.

\section{Concluding Remarks}

The wind tunnel facilities of NASA Lewis are specially suited for propulsion, and have many unique characteristics. The planned rehabilitation and upgrade of the facilities will enhance their. capability to continue to contribute to the leading edge of aeropropulsion research.

\section{References}

1. Yuska, J. A.; Diedrich, J. H., and Clough, N., "Lewis 9 - by 15-Foot V/STOL Wind Tunnel," NASA TM-X-2305, 1971.

2. Heidmann, M.F., and Dietrich, D.A., "Simulation of Flight-Type Engine Fan Noise in the NASA Lewis 9 by 15 Anechoic Wind Tunnel," NASA TM-X-73540, 1976.

3. Swallow, R.J., and Aiello, R.A., "NASA Lewis 8 by 6 Foot Supersonic Wind Tunnel," NASA TM-X-71542, 1974.

4. Dittmar, J.H., "Further Comparison of Wind Tunnel and Airplane Acoustic Data for Advanced Design High Speed Propeller Models," NASA TM-86935, 1985.

5. Aiello, R.A., "NASA Lewis 10 by 10 Foot Supersonic Wind Tunnel," NASA TM-X-71625, 1974.

6. NASA Icing Research Tunnel. (Facility description available on request from Lewis Research Center.)

7. Chamberlin, R., "The Altitude Wind Tunnel (AWT) - A Unique Facility for Propulsion System and Adverse Weather Testing, "AIAA Paper 85-0314, 1985.

8. Cullom, R.R., and Lezberg, E.A., "Calibration of Lewis Hypersonic Tunnel Facility at Mach 5, 6, and 7," NASA TN-D-7100, 1972. 


\title{
ORIGINAL PAGE IS \\ OF POOR QUAIITY
}

$\begin{array}{ll}\text { 9x15 ft WIND TUNNEL } & \text { MACH } 0-0.2 \\ 8 \times 6 \mathrm{ft} \text { WIND TUNNEL } & \text { MACH } 0.4-2.0 \\ \text { 10x10 WIND TUNNEL } & \text { MACH } 2.0-3.5 \\ \text { ICING RESEARCH TUNNEL } & 0-300 \text { KNOTS } \\ \text { lxl ft WIND TUNNEL } & \text { MACH } 1.3-4.0 \\ \text { CENTRAL AIR SYSTEM } & \end{array}$

\author{
$76 \mathrm{lb} / \mathrm{sec}$ AT $450 \mathrm{psi}$ \\ $400 \mathrm{lb} / \mathrm{sec}$ AT $150 \mathrm{psi}$ \\ $500 \mathrm{lb} / \mathrm{sec}$ AT $40 \mathrm{psi}$ \\ $325 \mathrm{lb} / \mathrm{sec}$ AT 3 in. HG ABSOLUTE
}

Figure 1. - Lewis Research Center Aeropropulsion Wind Tunnels.

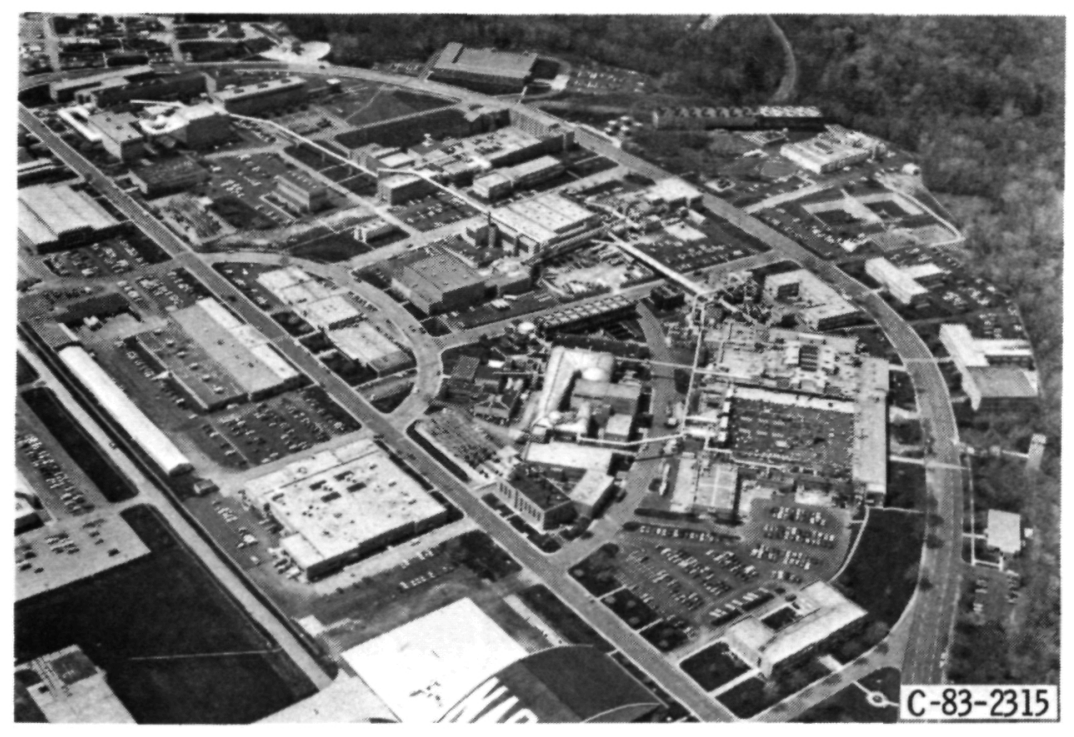

Figure 2. - Lewis Research Center facilities. 


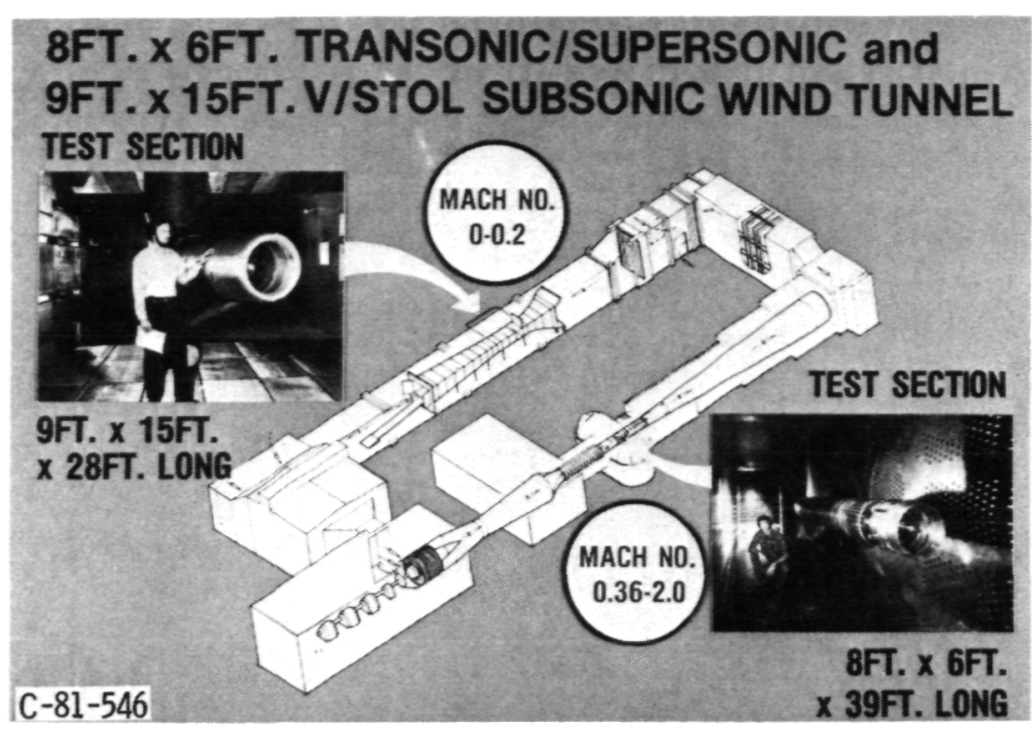

Figure 3. $-8 \times 6 / 9 \times 15$ Foot Wind Tunnel complex.

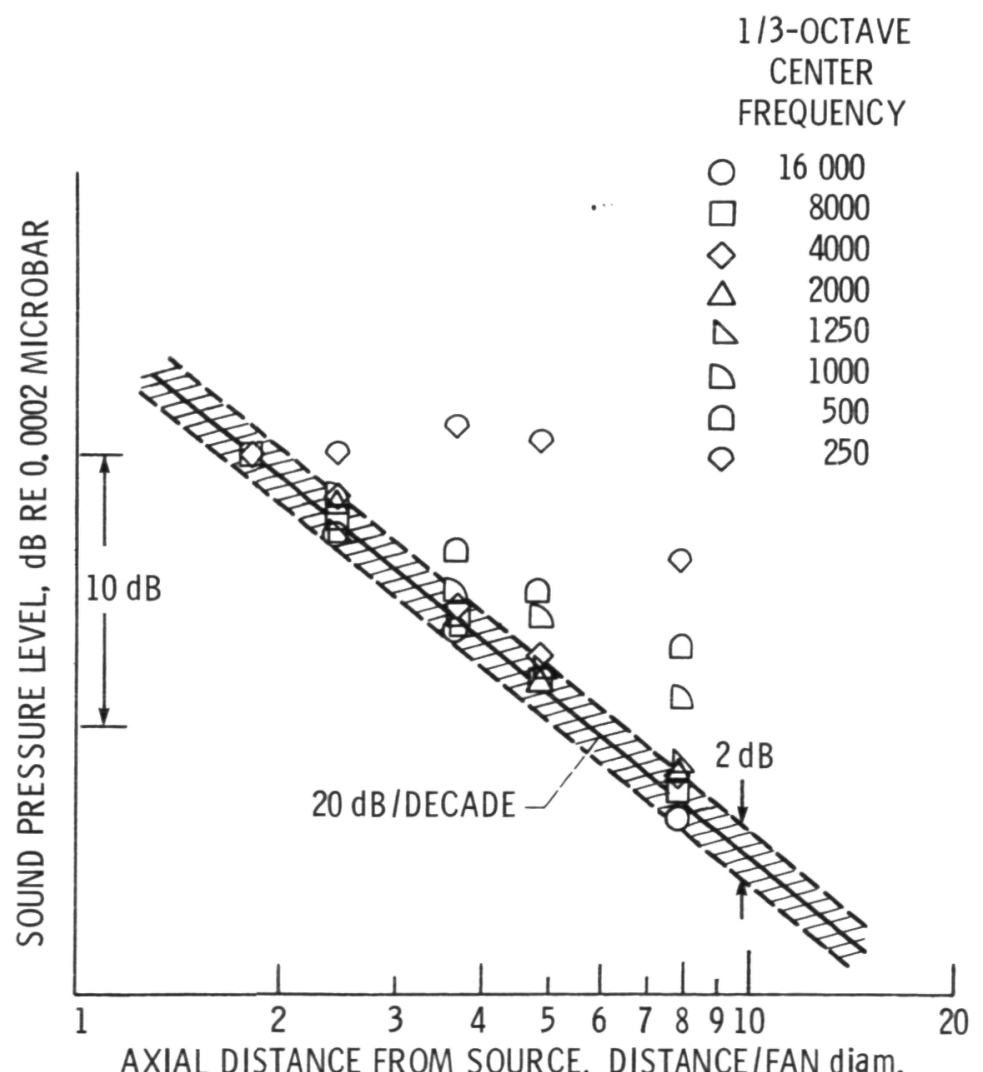

Figure 4. - Anechoic or free field properties of the $9 \times 15$ test section from acoustic evaluation tests for a broadband noise source without tunnel flow. 


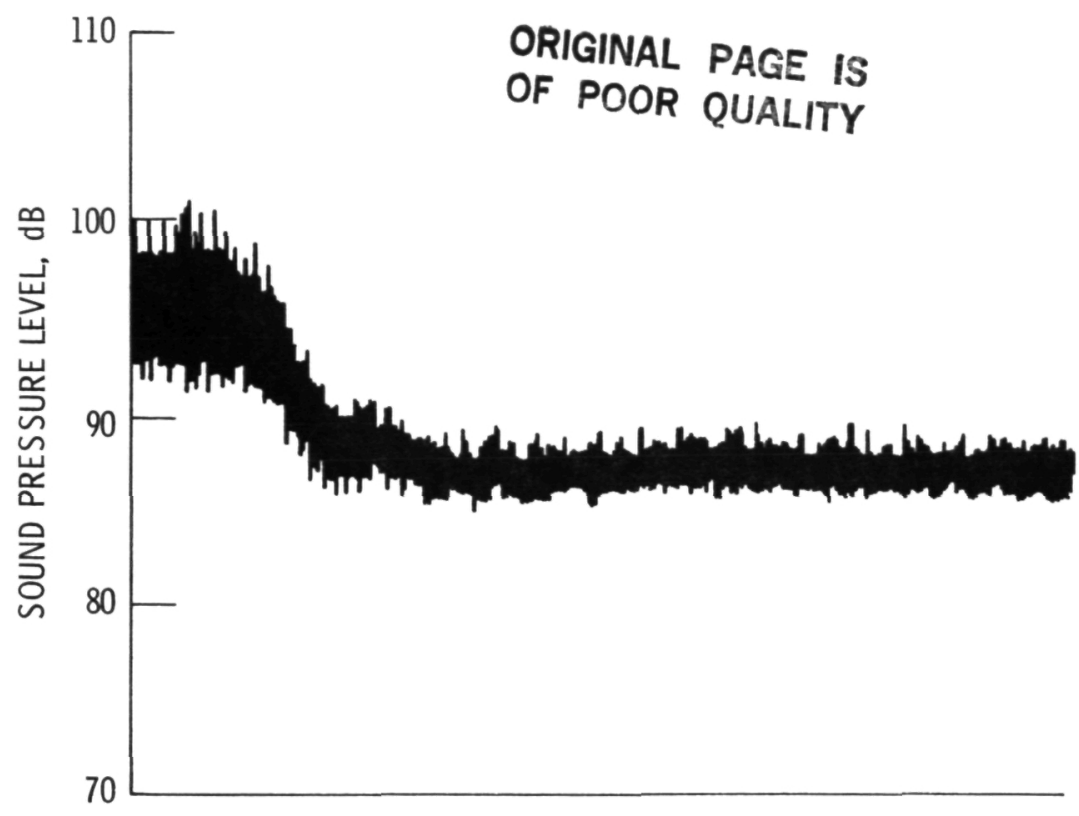

TIME $\longrightarrow$

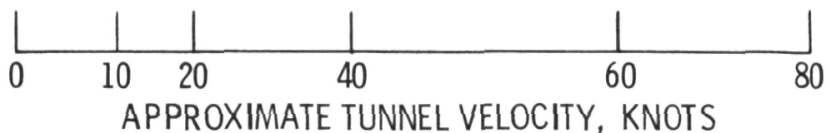

Figure 5. - Change in blade passage frequency tone level during tunnel start transient. One-third octave frequency level at $60^{\circ}$ from inlet axis. Fan speed $96 \%$ of design.

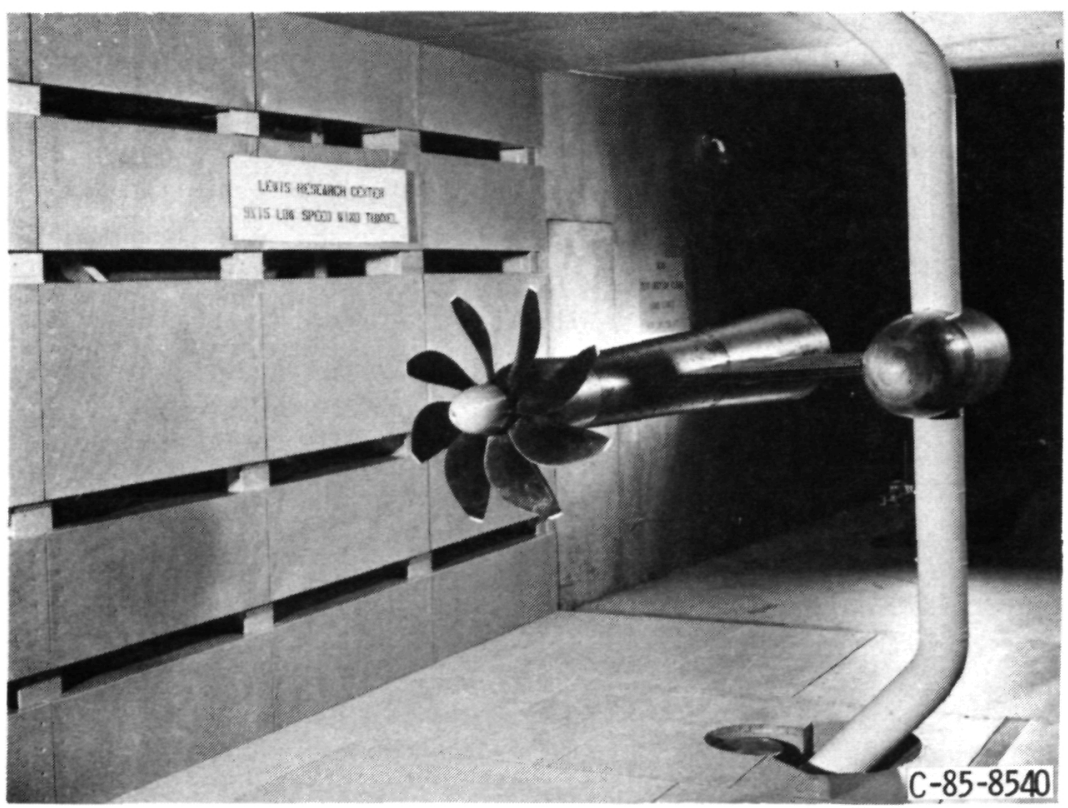

Figure 6. - ATP flight propeller model mounted in 9x15 Wind Tunnel for acoustic and perfor mance testing at take off conditions. 


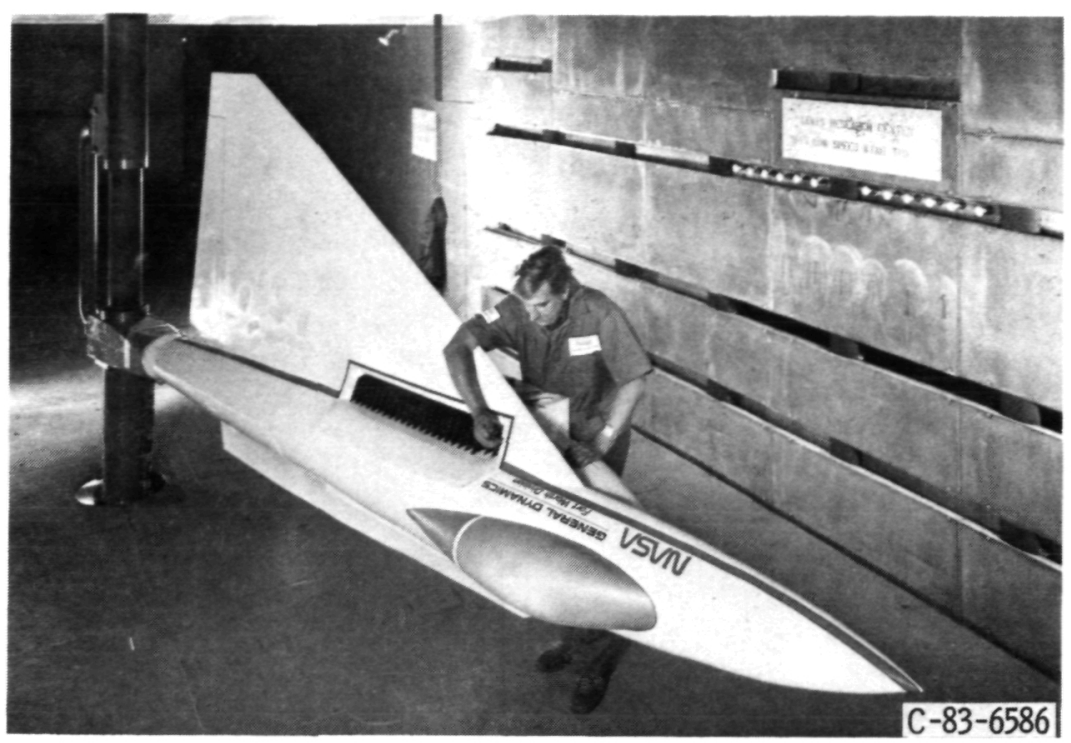

Figure 7. - STOVL ejector/wing concept mounted in 9x15 Foot Wind Tunnel to evaluate static and dynamic perfor mance.

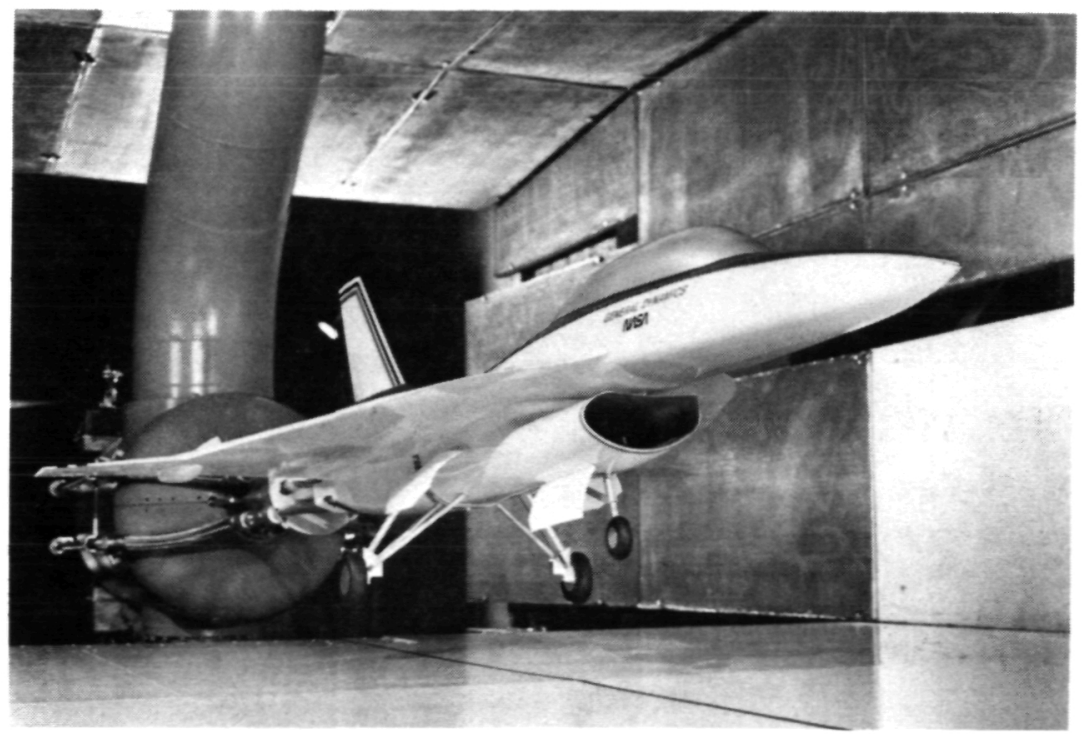

Figure 8. - Thrust reversal-hot gas reingestion model in 9x15 Foot Wind Tunnel. 

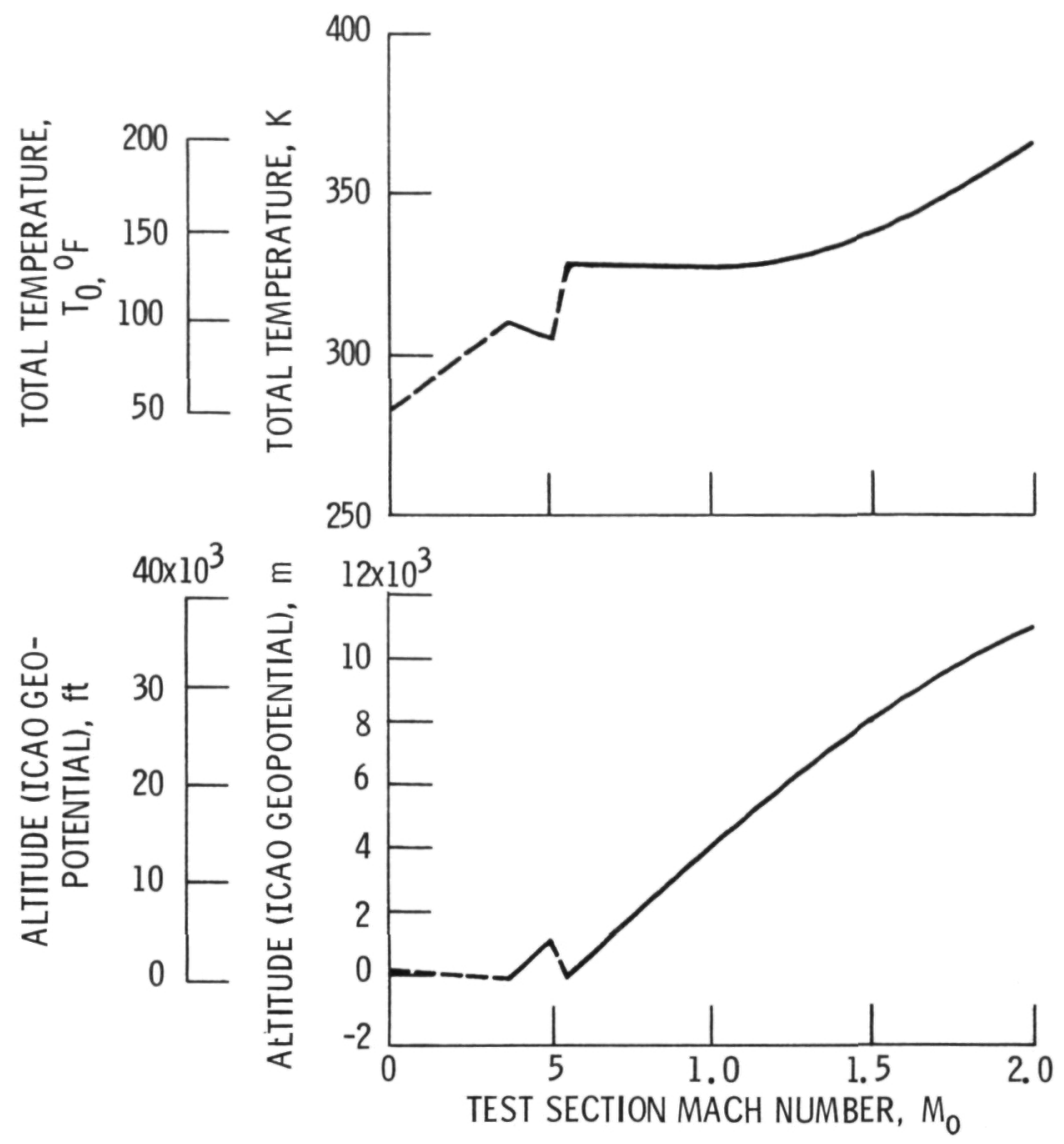

Figure $9 .-8$ by 6 Foot wind tunnel altitude and total temperature variation with Mach number. 
ORIGINAL PAGE IS

OF. POOR QUALITY

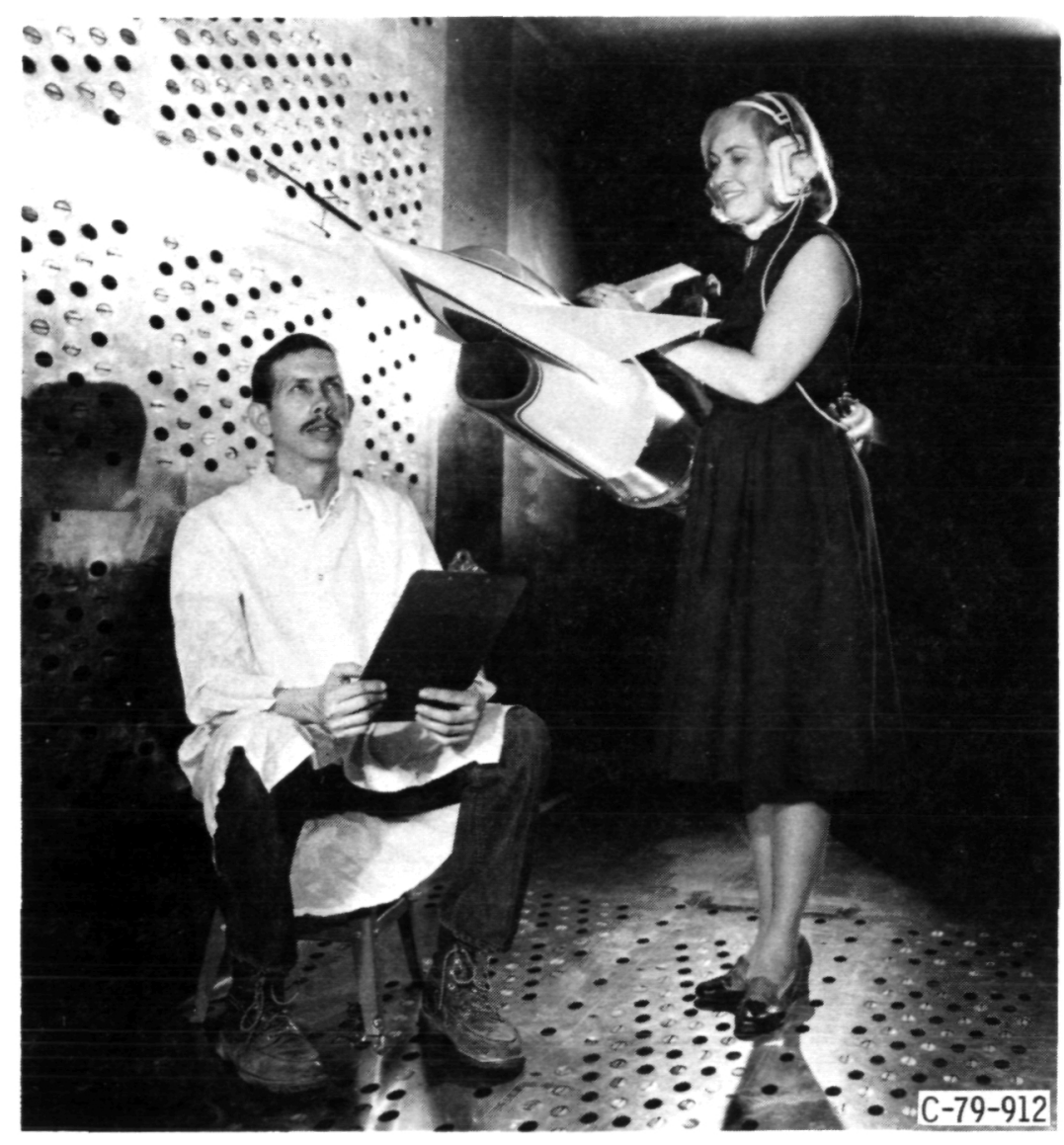

Figure 10. - Himat inlet model mounted in the $8 \times 6$ Foot Wind Tunnel for testing at high angles of attack and yaw. 


\section{ORIGINAL PAGE IS
OF POOR QUALITY}

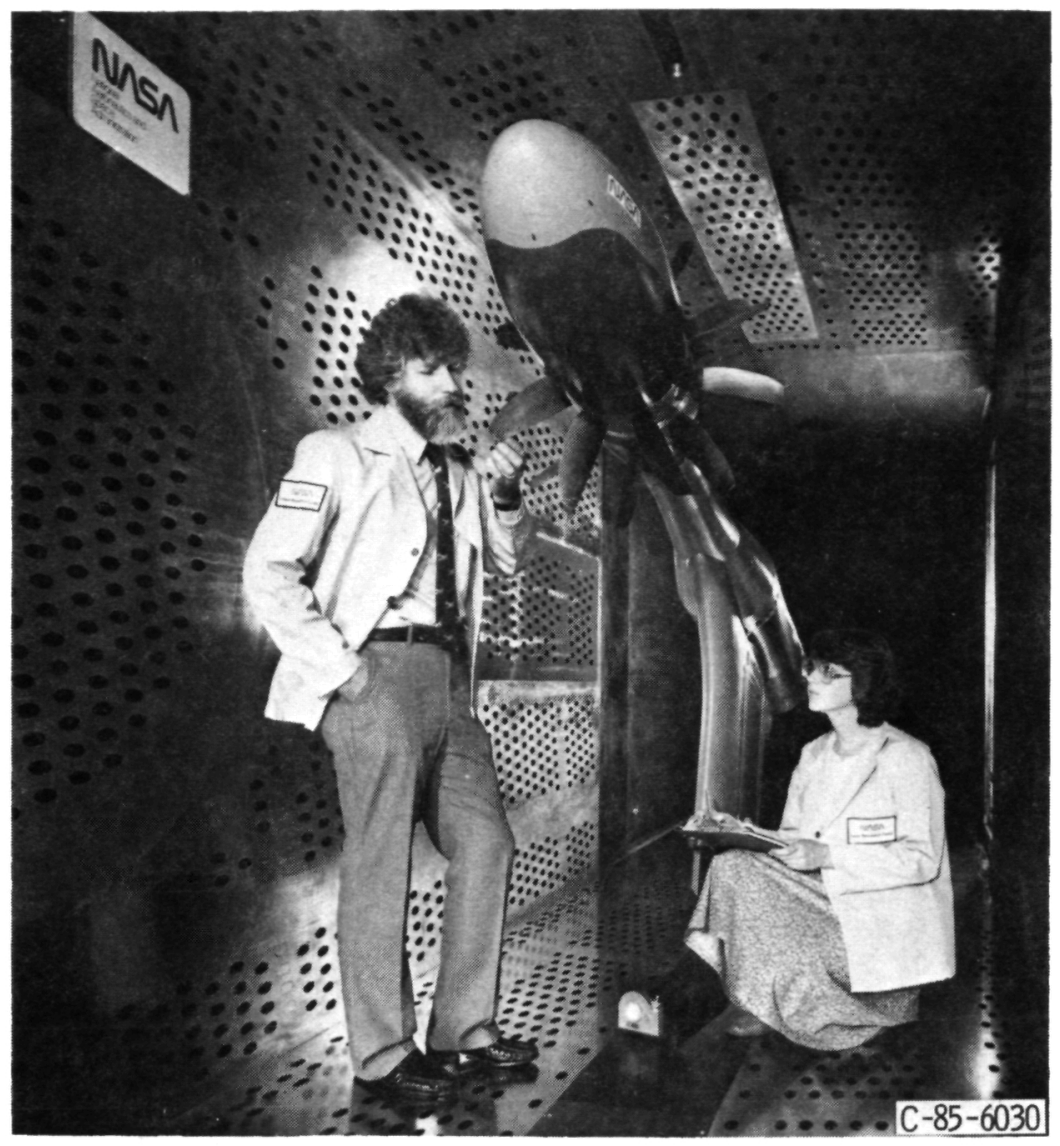

Figure 11. - Counter rotation propeller model mounted in the $8 \times 6$ Foot Wind Tunnel. 


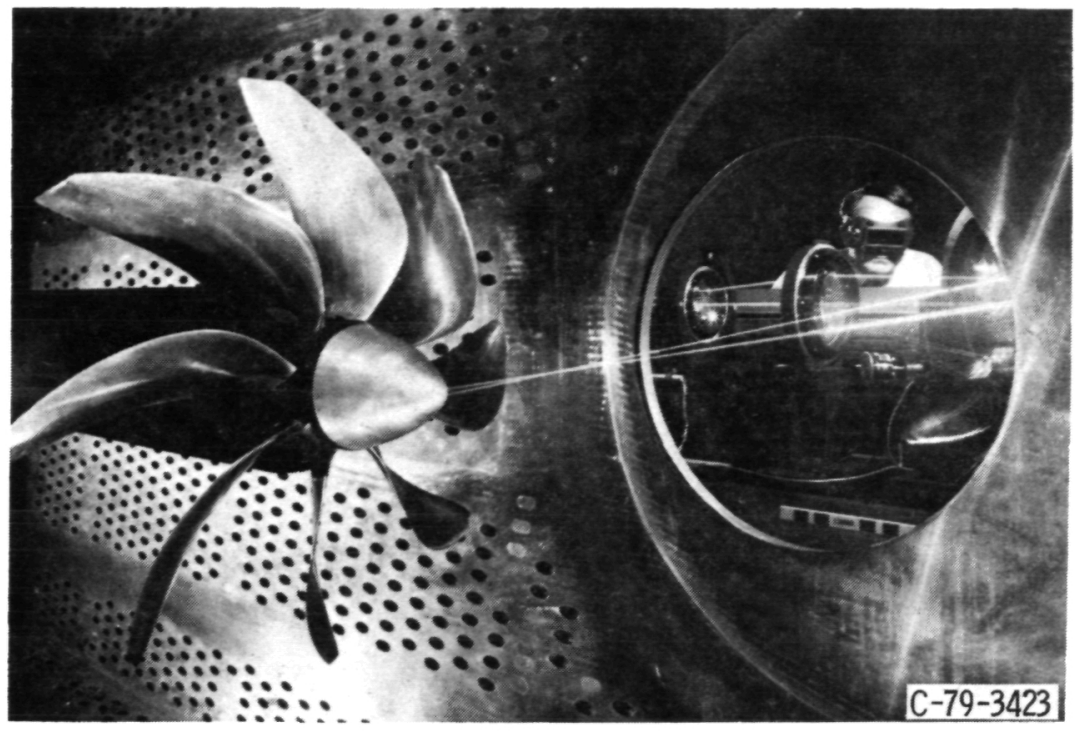

Figure 12. - LDV measurement of interblade flowfield on transonic single rotation propeller.

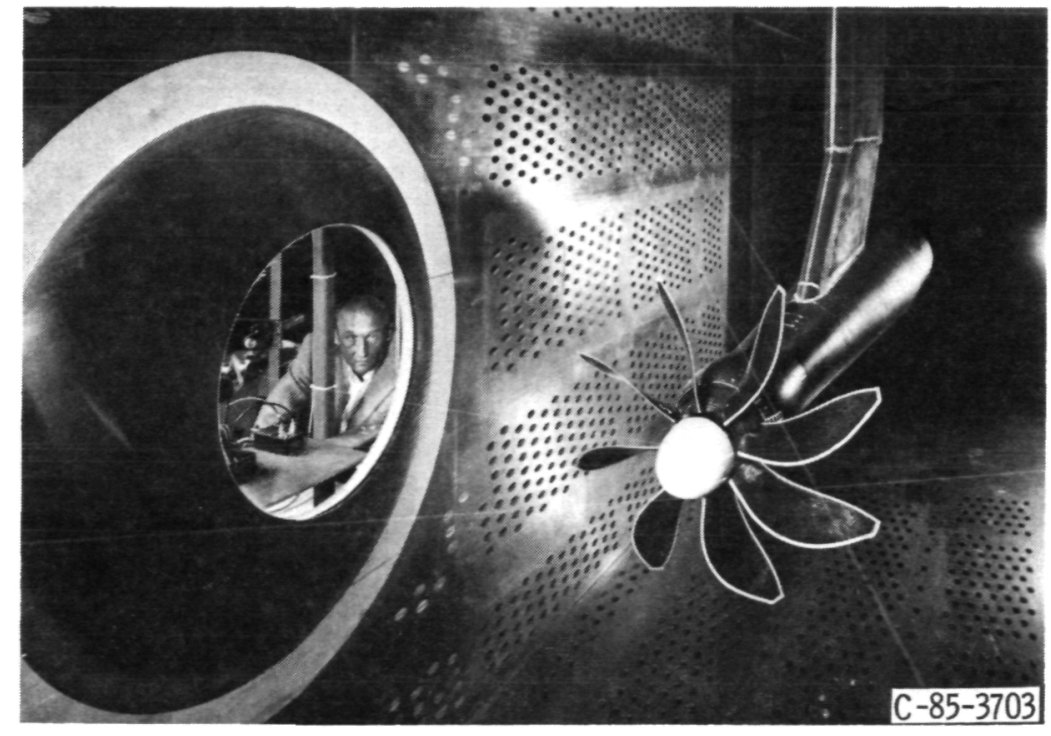

Figure 13. - Laser measurement of propeller static and dynamic deflection during $8 \times 6$ Foot Wind Tunnel testing. 


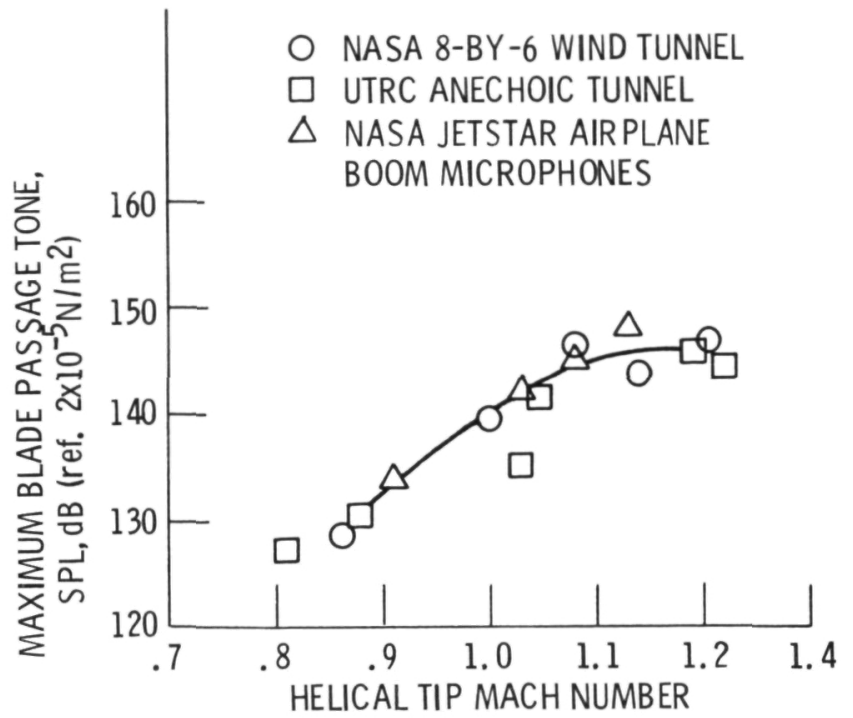

Figure 14. - Maximum blade passage tone variation with helical tip Mach number, SR-3 propeller corrected to fuselage conditions.

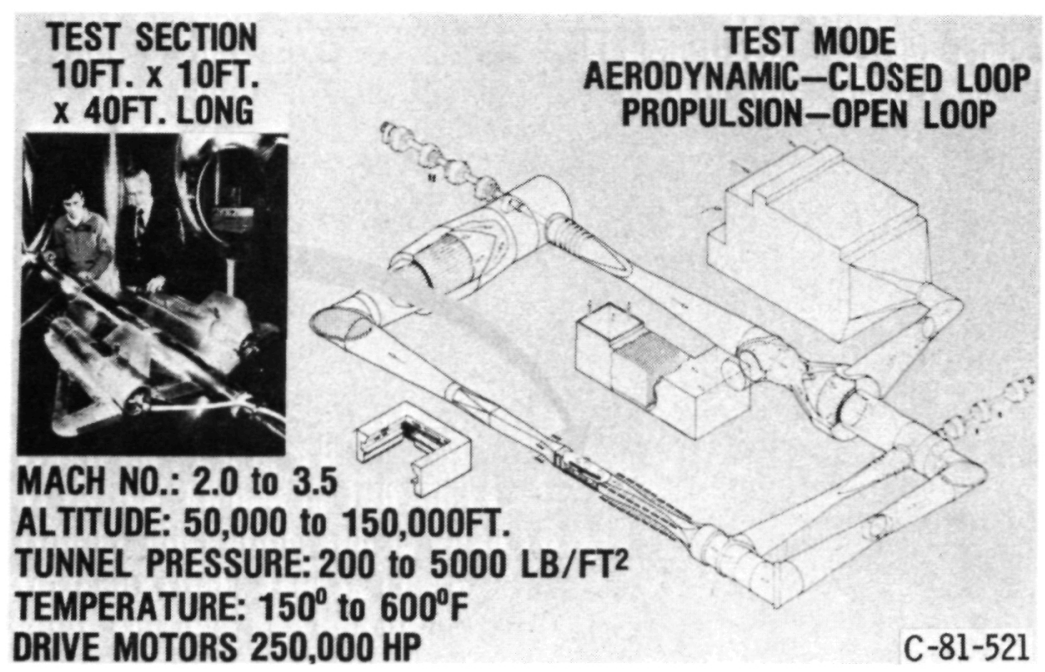

Figure 15. - 10x10 Foot Supersonic Propulsion Wind Tunnel. 

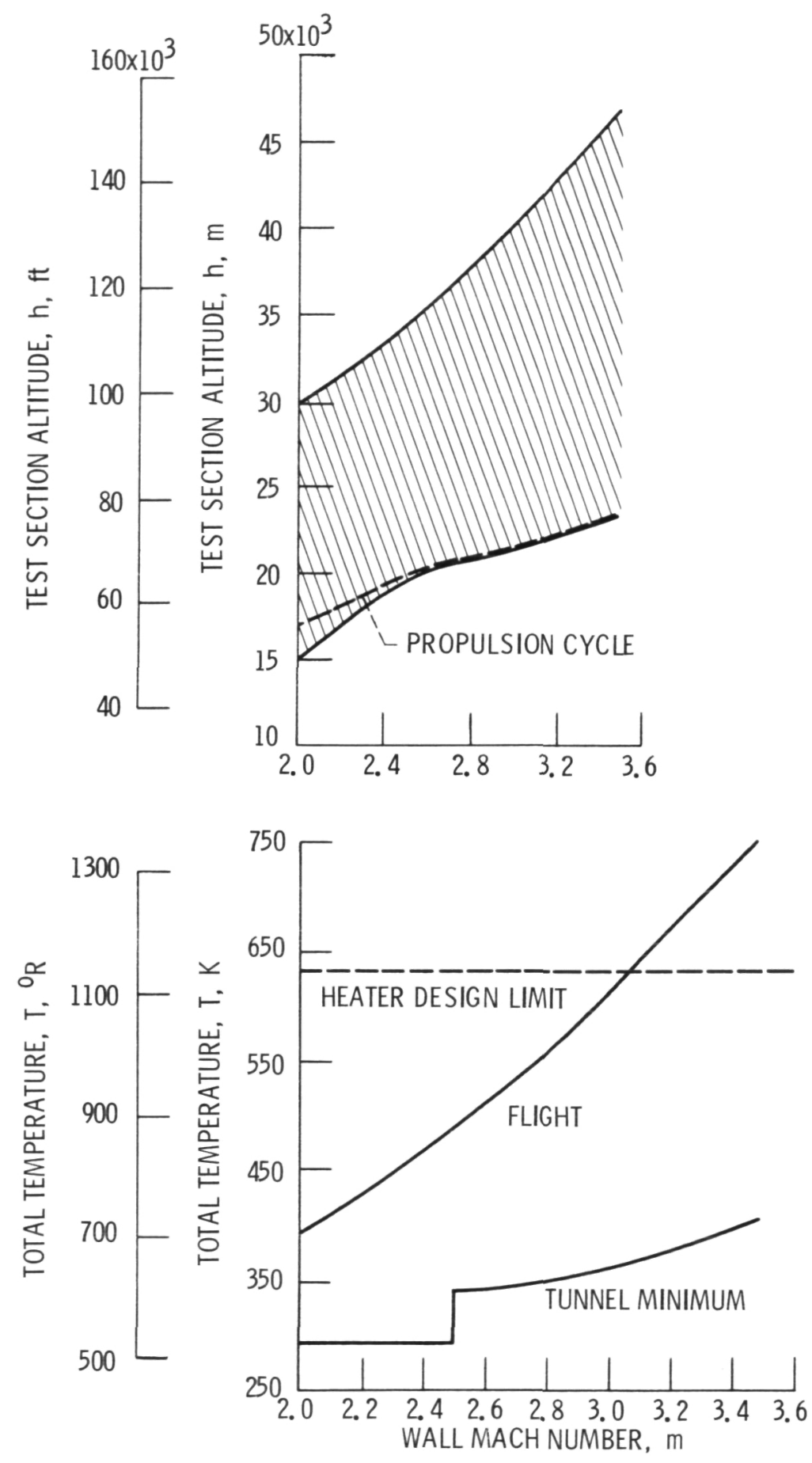

Figure 16. - 10x10 Foot supersonic wind tunnel capability to simulate pressure altitude and temperature. 


\section{ORIGINAL PAGE IS \\ OF POOR QUALITY}

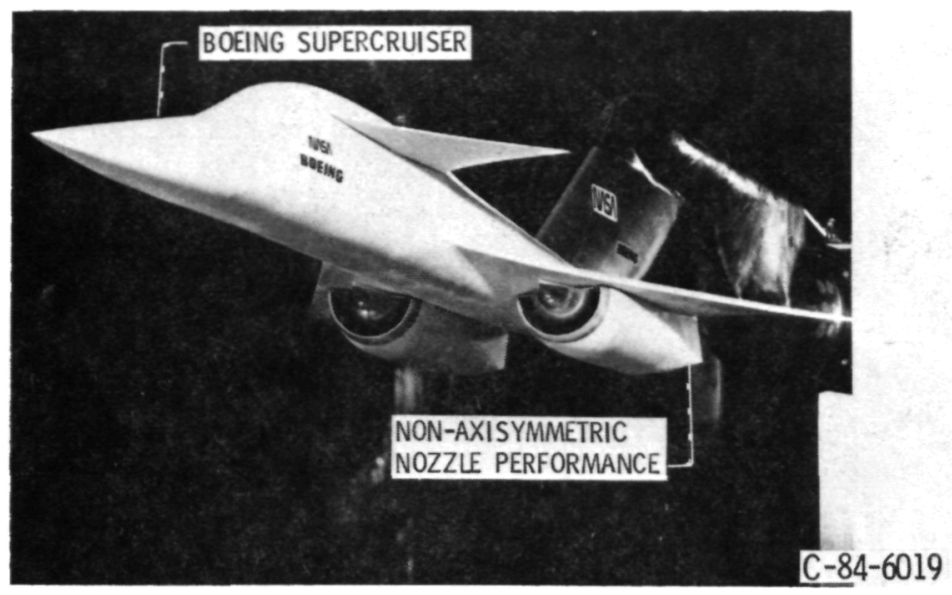

Figure 17. - Propulsion integration model installed in 10x10 Foot Supersonic Wind Tunnel to determine jet effects on installed nozzle performance.

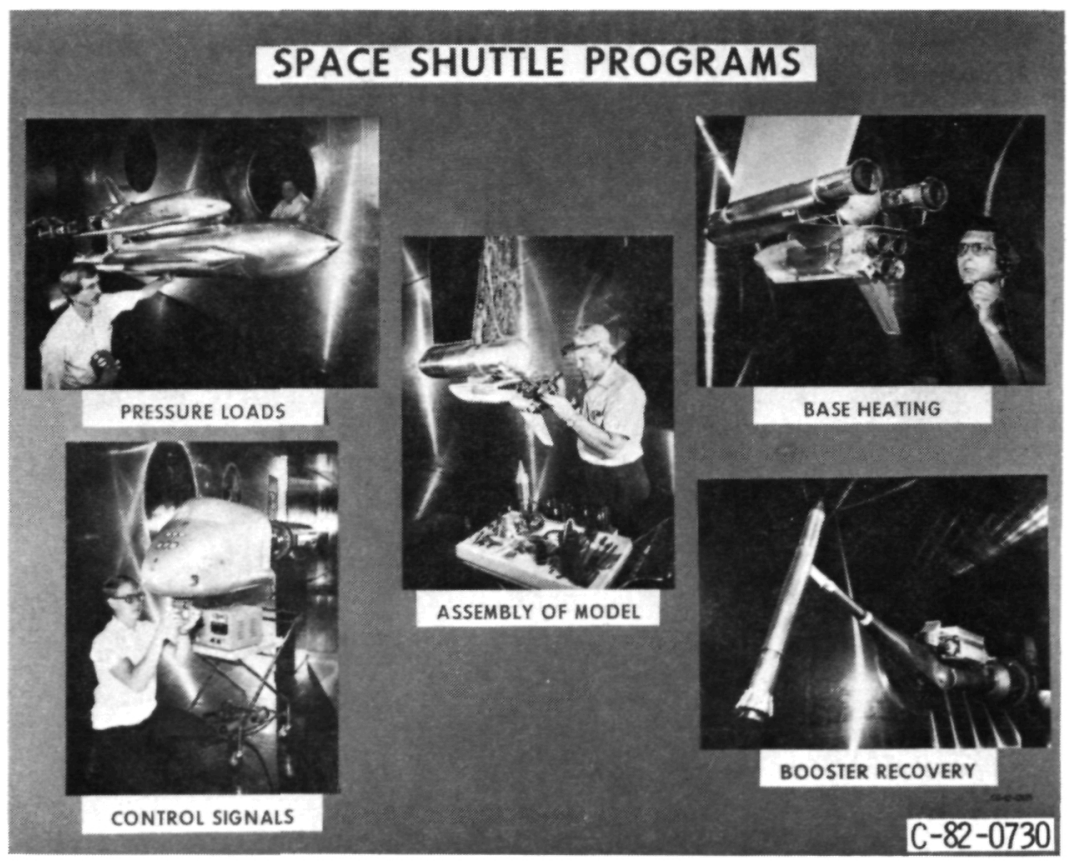

Figure 18. - Aerodynamic and propulsion testing in the 10x10 Foot Supersonic wind tunnel in support of Space Shuttle development. 


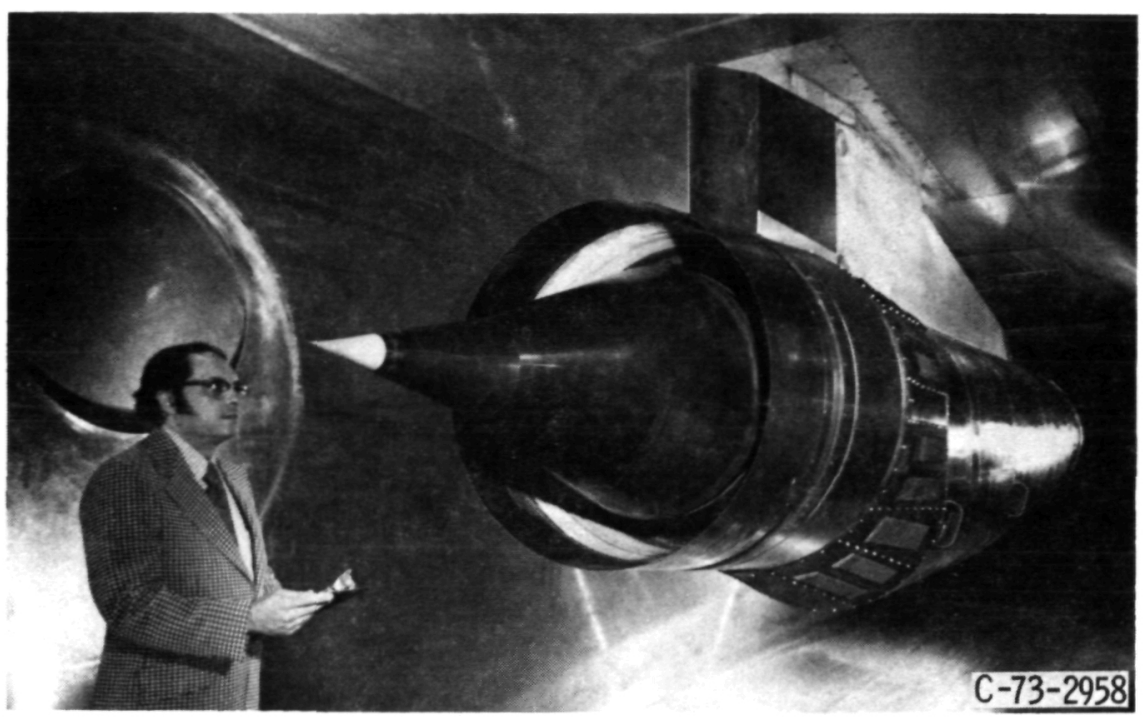

Figure 19. - Propulsion system test in the 10x10 Super sonic wind tunnel on an inlet with internal super sonic compression and a TF30 afterburning turbofan engine.

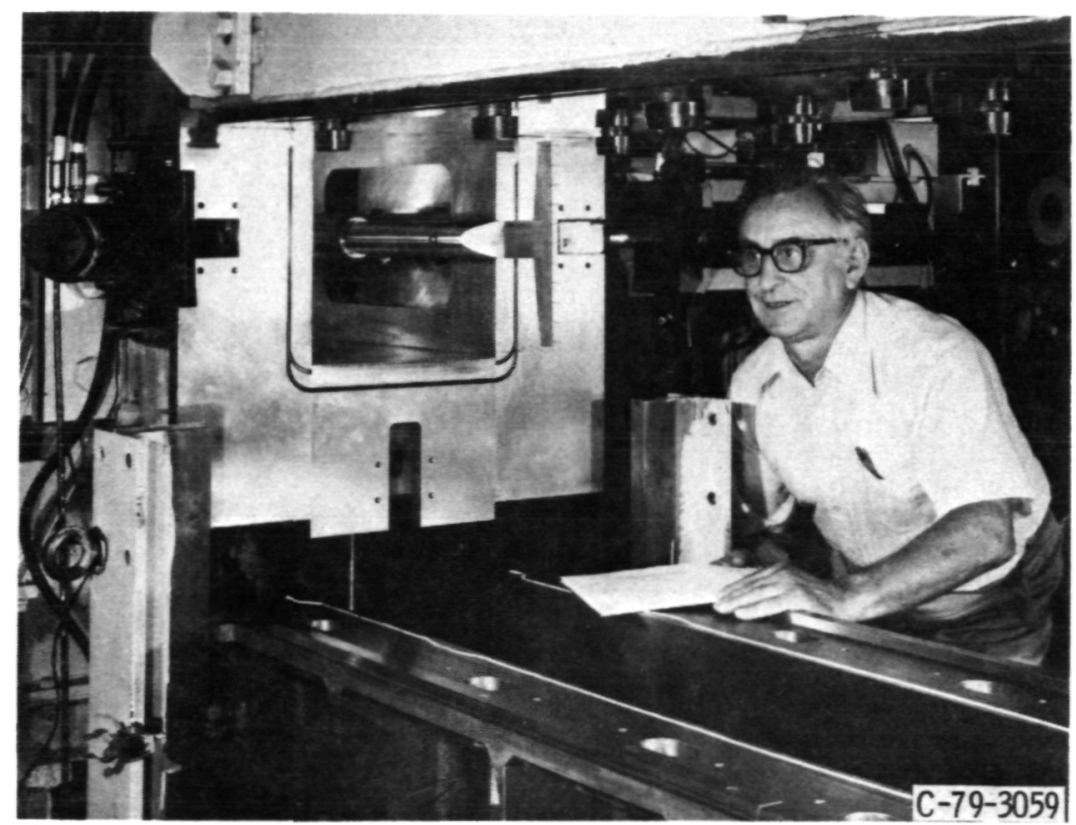

Figure 20. - 1xl Foot Supersonic wind tunnel. 


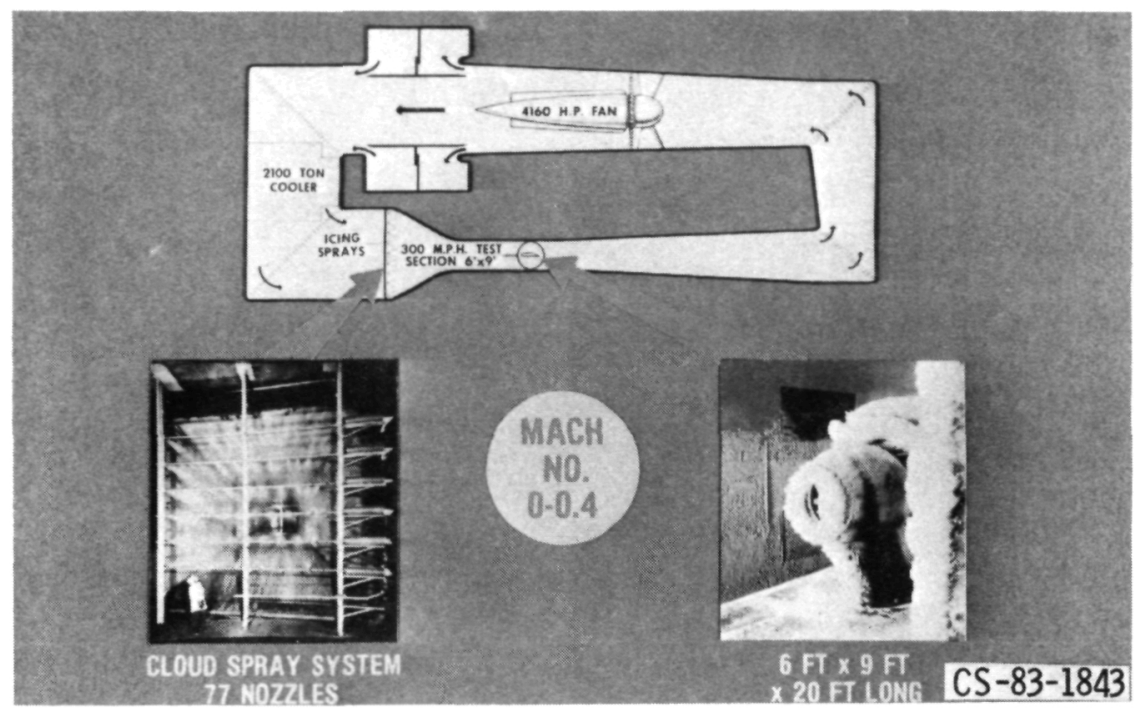

Figure 21. - Icing Research Tunnel.

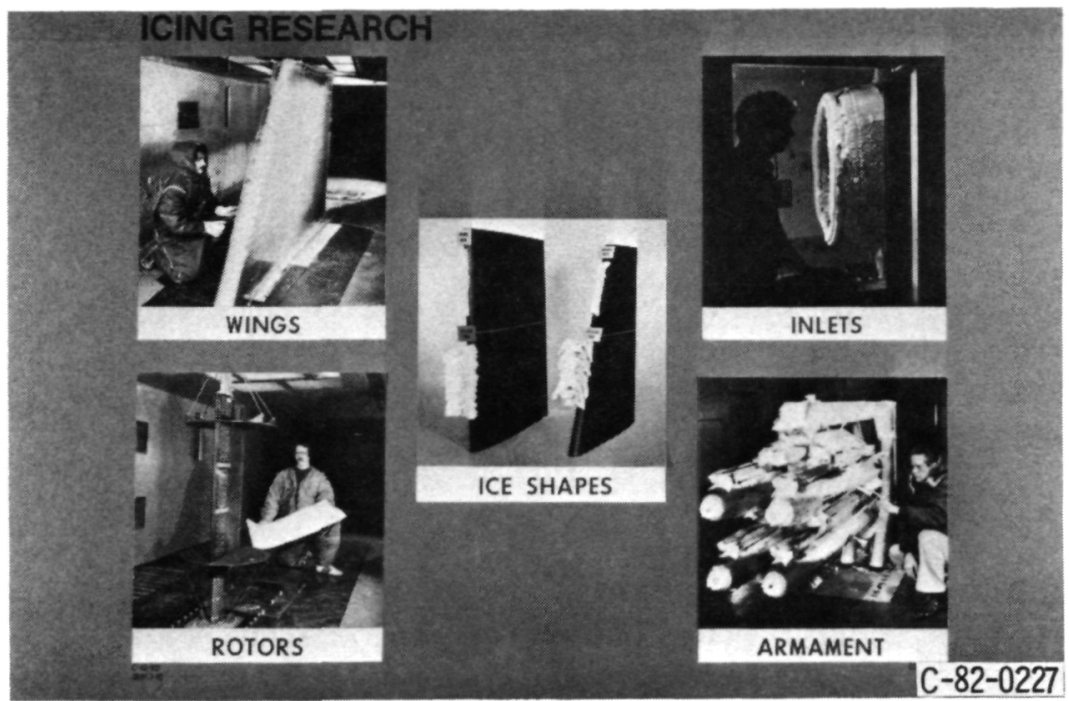

Figure 22. - Icing Research Tunnel testing capability. 


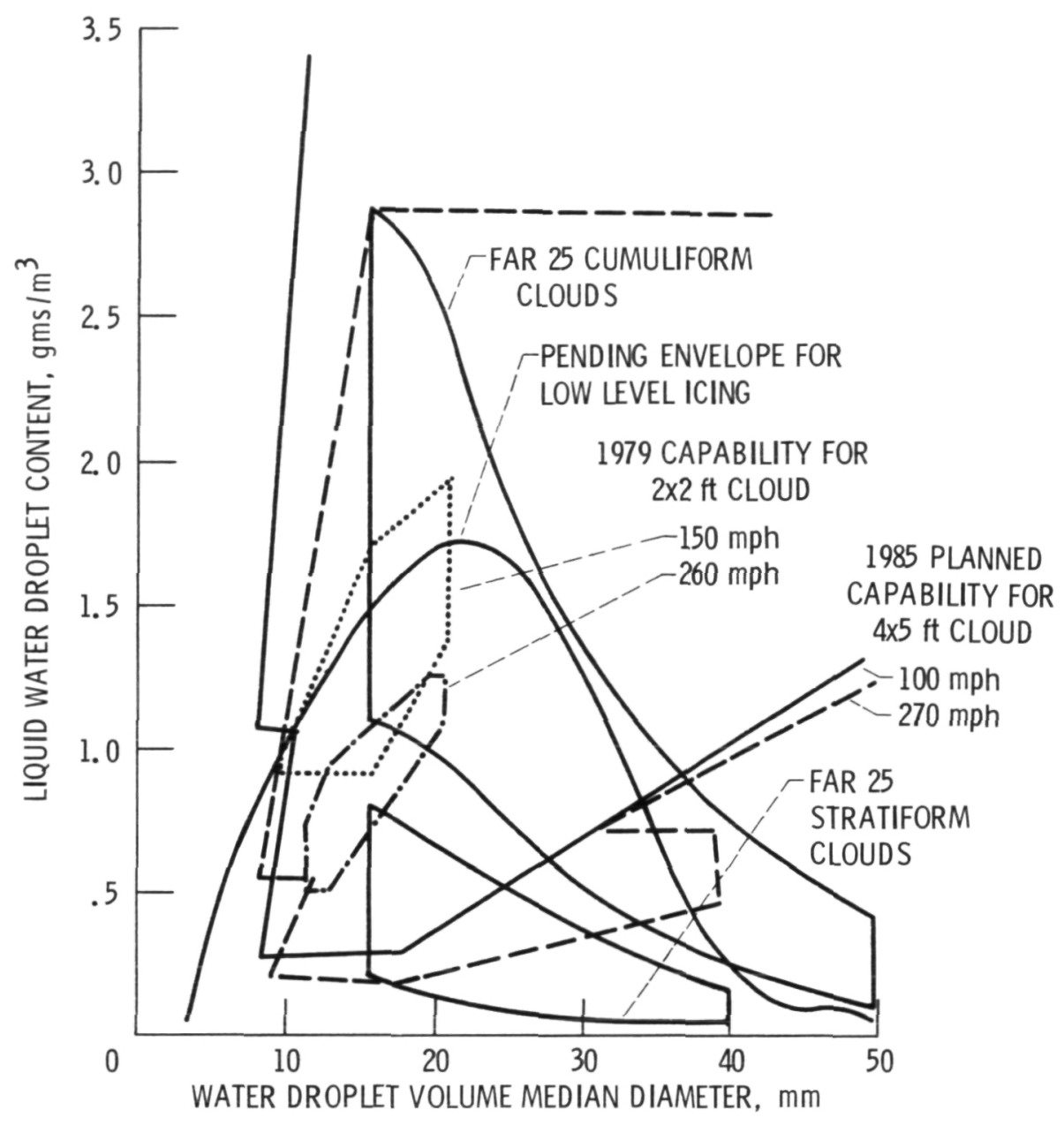

Figure 23. - Comparison of 1979 icing research tunnel cloud simulation and planned performance after 1985 rehabilitate. 


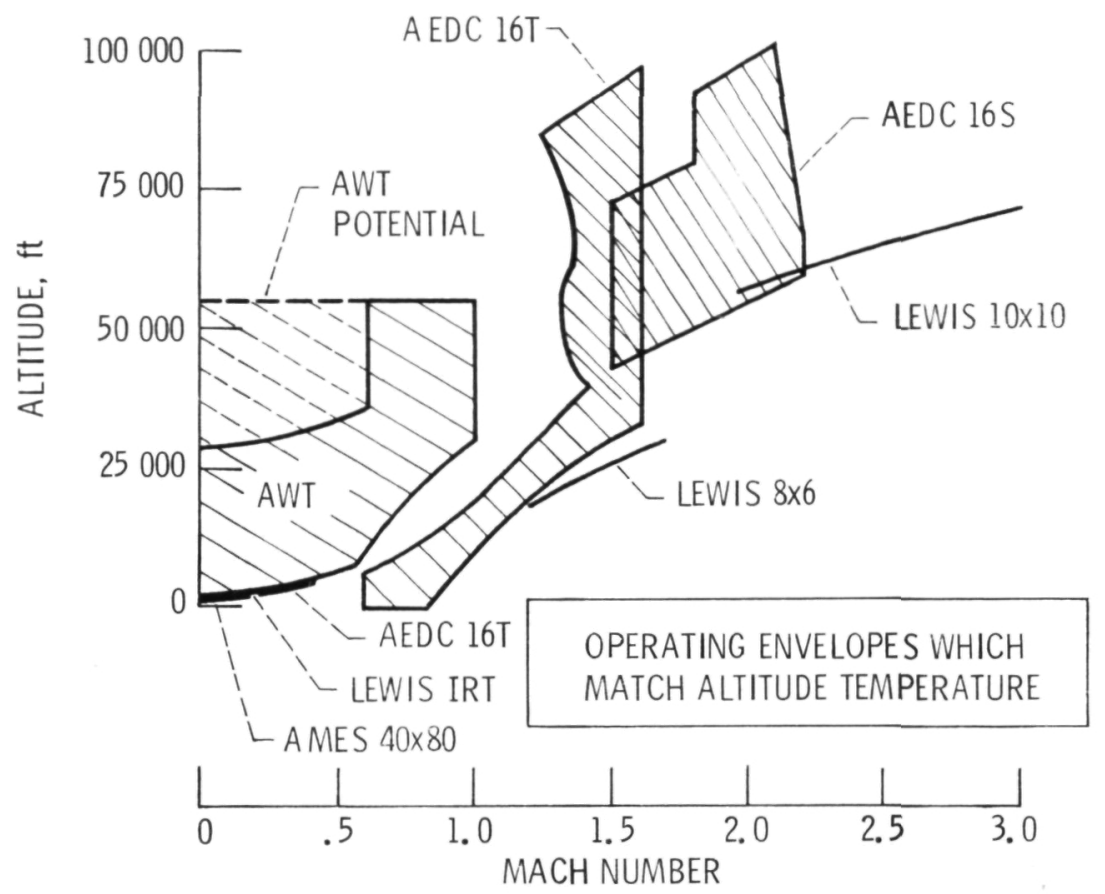

Figure 24. - U. S. Propulsion wind tunnel capability to simulate actual flight temperatures.

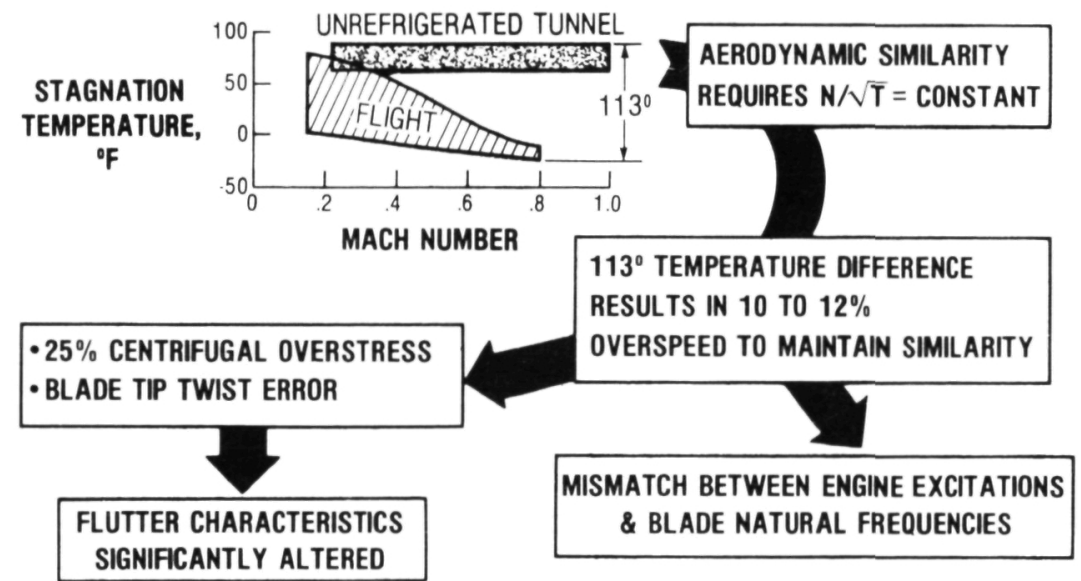

Figure 25. - Ambient temperature effect on wind tunnel testing of turboprop systems. 


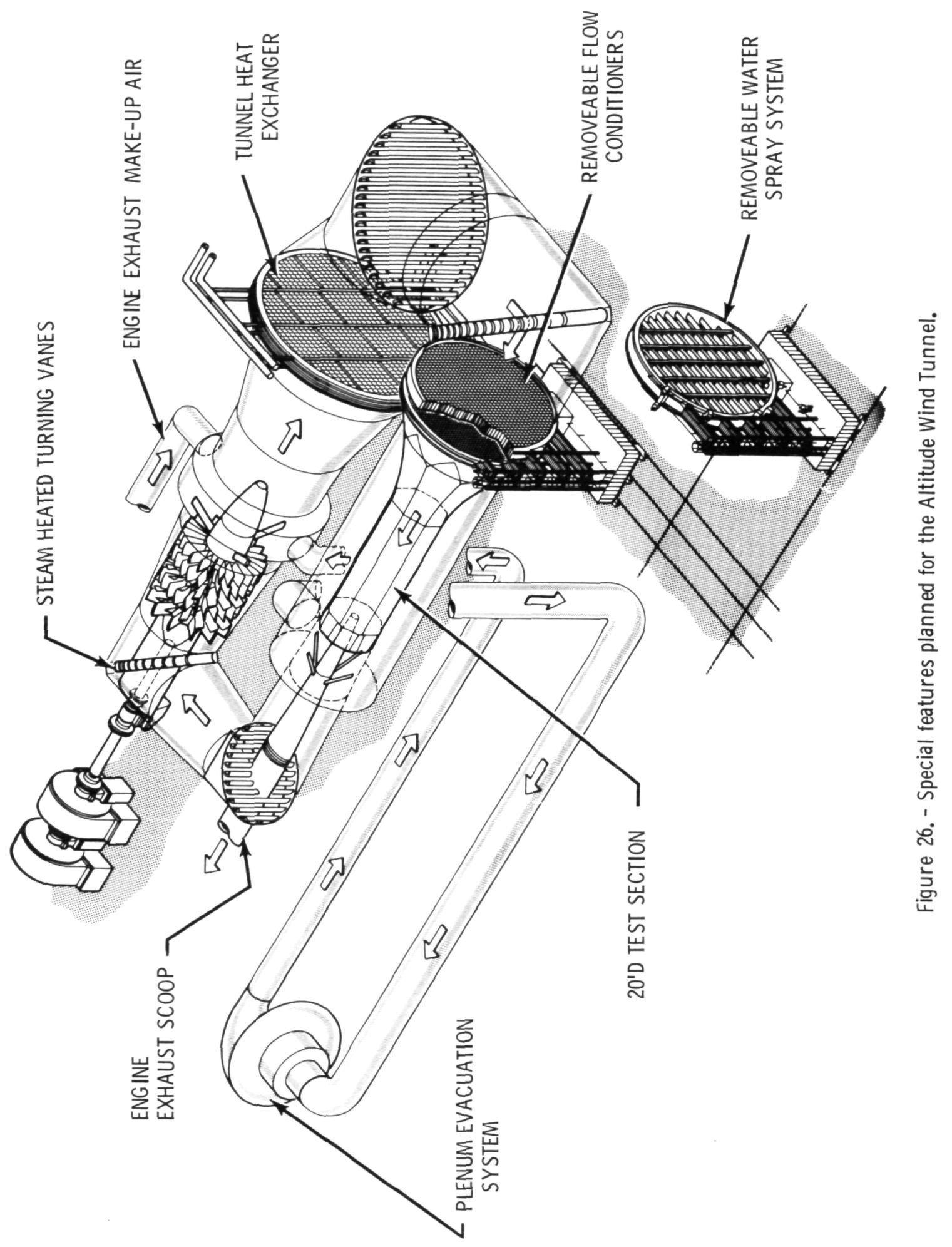




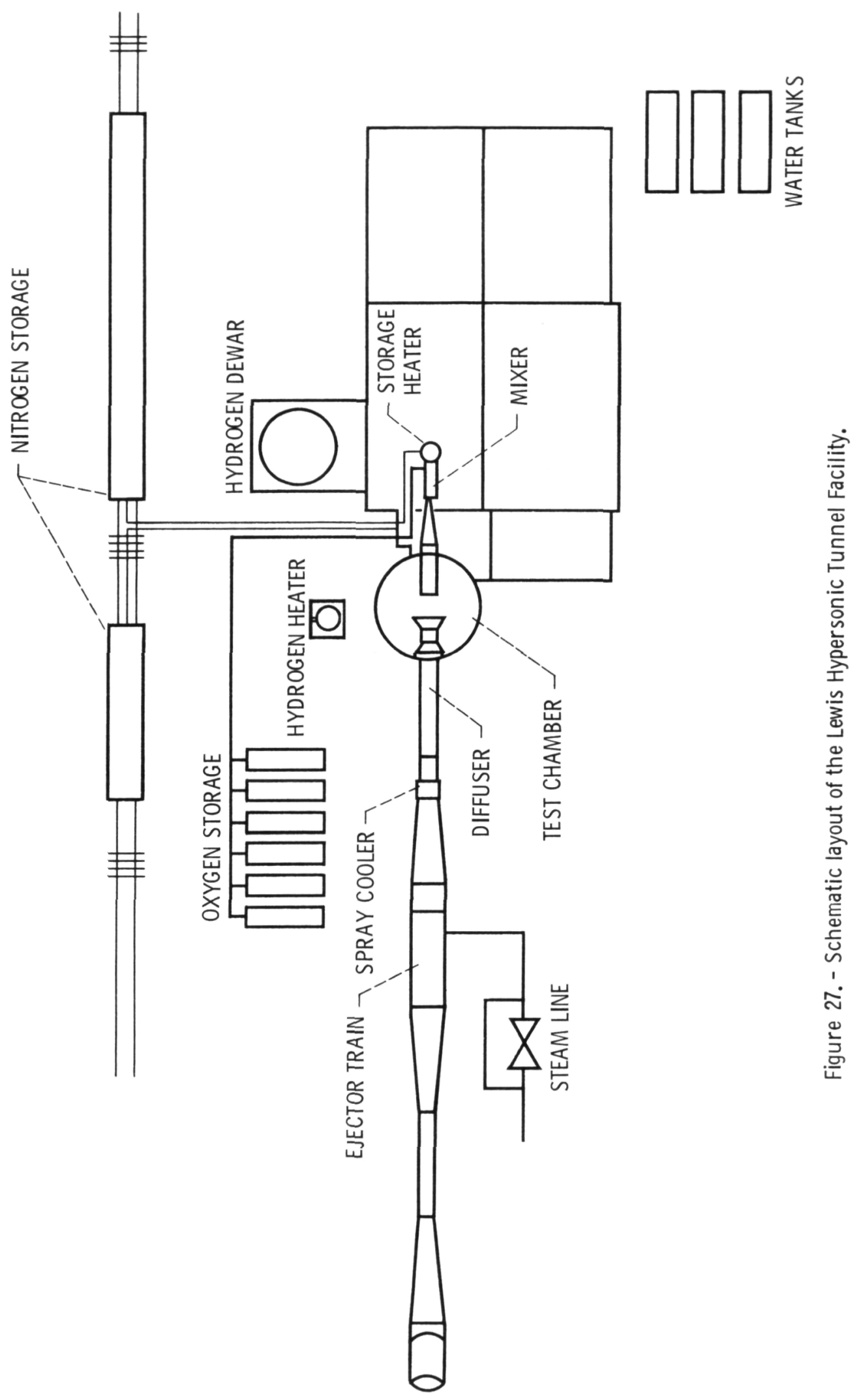




\section{HYPERSONIC TUNNEL FACILITY}

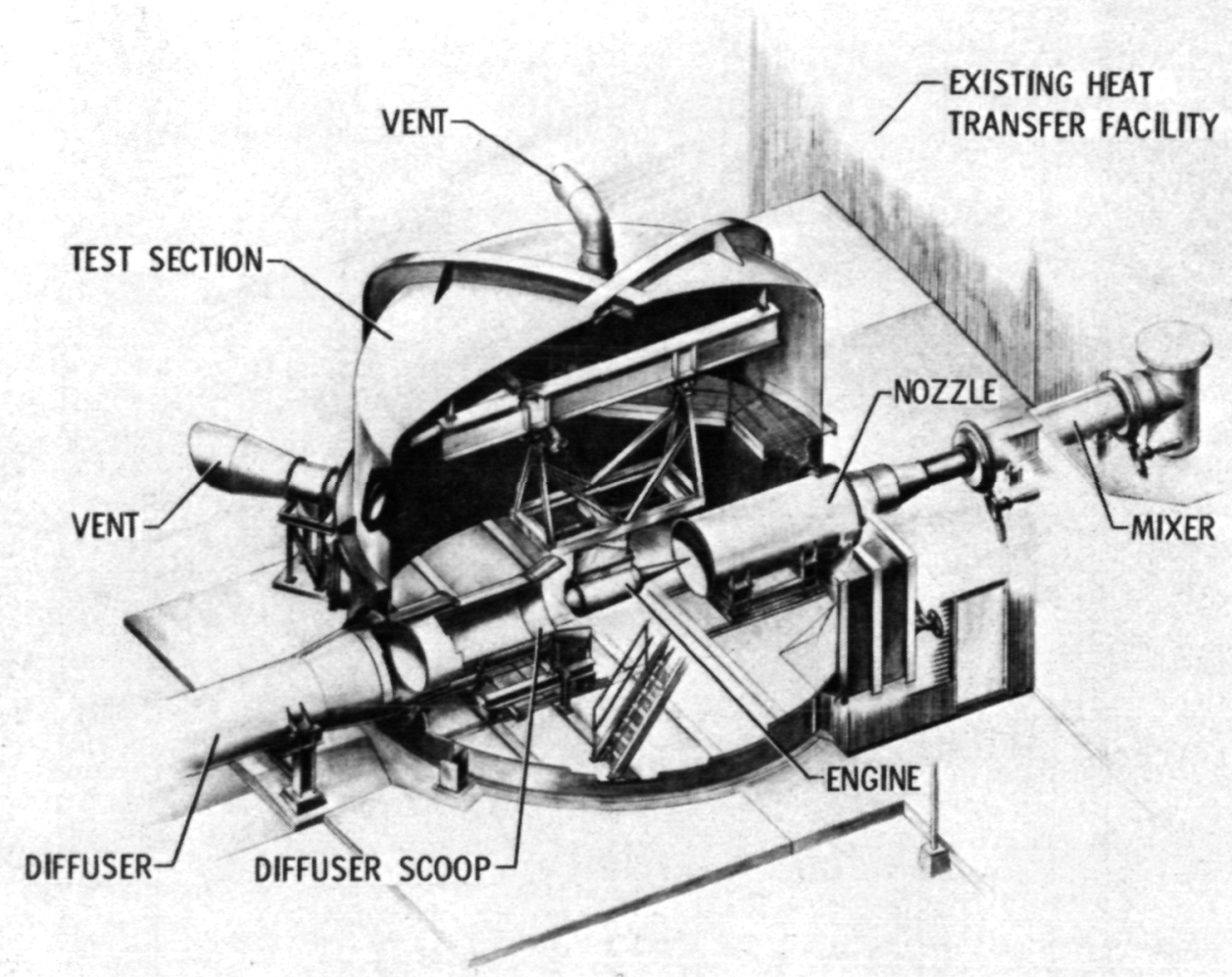

Figure 28. - Freejet test section of the Lewis Hyper sonic Tunnel Facility. 


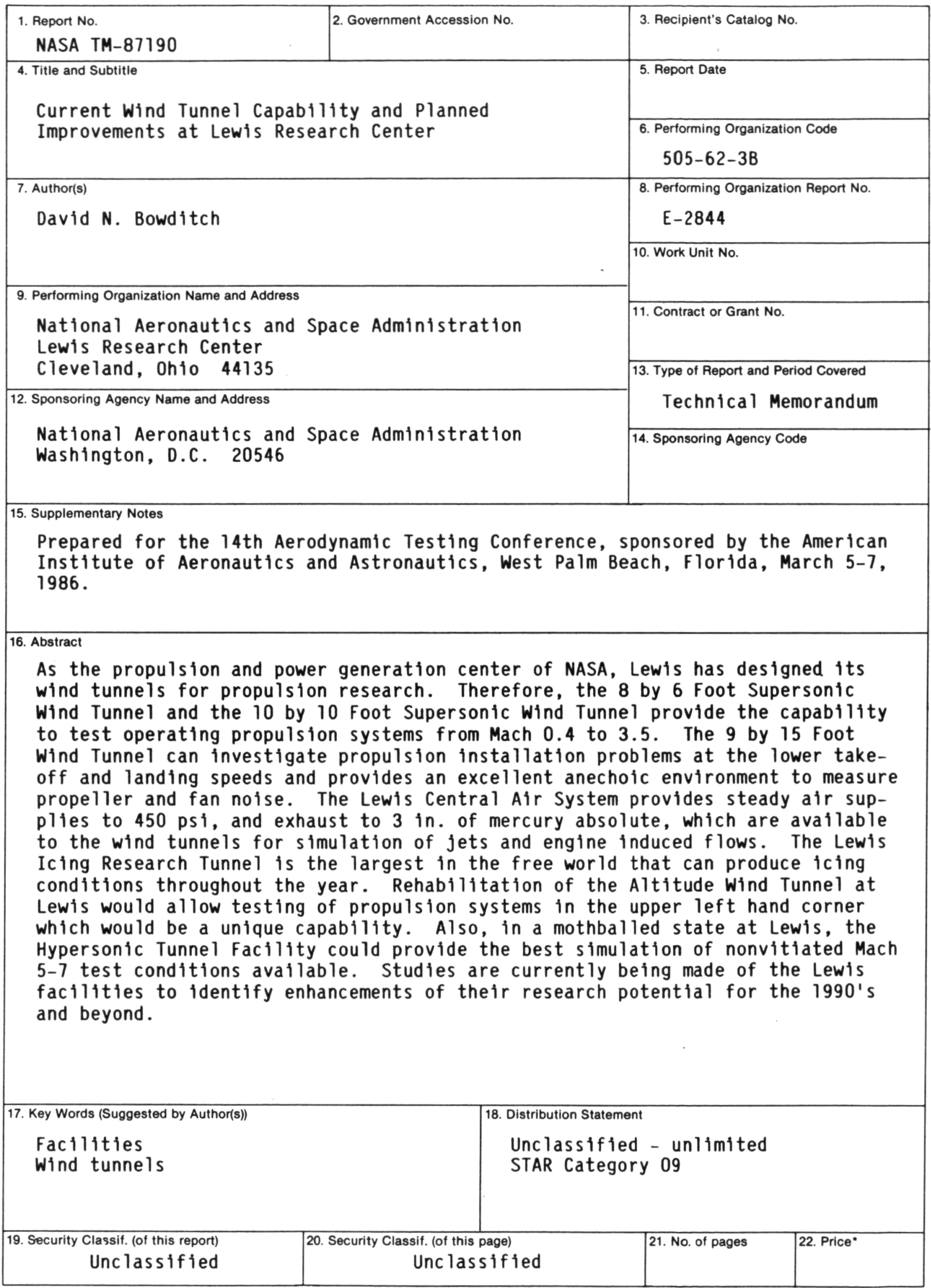

*For sale by the National Technical Information Service, Springfield, Virginia 22161 



\section{Lewis Research Center}

Cleveland. Ohio 44135

ADDRESS CORRECTION REQUESTED

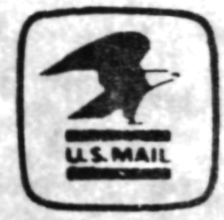

Official Business

Penalty for Private Use $\$ 300$

Postage and Fees Paid

National Aeronautics and

Space Administration

NASA-451 